\title{
Making productive use of exemplars: Peer discussion and teacher guidance for positive transfer of strategies
}

To, J., \& Carless, D. (2015). Making productive use of exemplars: Peer discussion and teacher guidance for positive transfer of strategies. Journal of Further and Higher Education, DOI: 10.1080/0309877X.2015.1014317

\begin{abstract}
Discussion of exemplars of student work is a productive means of explaining tacit knowledge and guiding students into the requirements of academic writing. Through two cycles of action research in a post- secondary institution in Hong Kong, this study examines how exemplars can be used to enhance student understanding of quality and to promote positive transfer of strategies and skills from exemplars to assessment task. Interventions included peer discussion, teacher-led interaction and student mini-presentations in relation to exemplars. To gauge perceptions of these processes, we collected data via open-ended surveys and focus group interviews with students, commentaries from a critical friend and a teacher-researcher reflective journal. Findings suggest that peer discussion and teacher guidance play a complementary role in engineering a supportive learning environment for positive transfer of insights. Peer discussion is useful in allowing students to generate ideas and negotiate meanings. Teacher guidance serves to explicate the characteristics of good quality work and to increase students' critical aware- ness of the differences between exemplars and their own writing. Teaching implications for dialogic use of exemplars are discussed, and some avenues for future exemplar-related research outlined.
\end{abstract}

Keywords: exemplars; quality; positive transfer; peer discussion; teacher guidance

\section{Introduction}

Students often find it difficult to understand assessment criteria and the nature of good quality work in their discipline. Under these circumstances, they face challenges in identifying and providing what teachers are looking for in an assessment task. A useful teaching strategy is to help students understand the nature and characteristics of quality through discussing and analysing exemplars of student work prior to tackling their own related task. Royce Sadler has been a particularly influential proponent of the value of 
using exemplars, and we adopt his definition of exemplars as 'key examples chosen so as to be typical of designated levels of quality or competence' (Sadler 1987, 200).

Exemplars of authentic student work illustrate different levels of performance and enable teachers to share tacit knowledge which may remain opaque to students (Sadler 2002). A powerful rationale for their use is that students need to gain experience in making judgements about work of different quality, create verbalised accounts of how various works could have been improved, and engage in evaluative conversations with teachers and other students (Sadler 2010). Criteria can seem highly abstract to students, whereas exemplars represent the concrete embodiment of standards and accordingly can support students in developing their assessment literacy (Price et al. 2012).

To date, research on exemplars is relatively modest (Handley and Williams 2011), but appears to be gaining some momentum. From a review of literature, we identified two key issues in productive use of exemplars: what kinds of discussion are useful in clarifying the characteristics of good quality work and is there a danger that students may copy or imitate exemplars rather than transferring insights to their own work? Following on from these issues, this study explores the use of exemplars to enhance students' awareness of, and ability to produce, good quality academic writing. Action research was chosen as the approach because iterative cycles facilitated teacher learning from the data collection and reflection on the intervention (Kemmis and McTaggart 1988). The context of the study is an academic English course in a post-secondary institution in Hong Kong. Data for the study were gathered using a range of qualitative methods: open-ended surveys, focus group interviews with students, commentaries from a critical friend, and a teacher-researcher reflective journal. The article particularly seeks to discuss pedagogical implications for facilitating positive transfer of strategies from the use of exemplars to students' own work.

\section{Using exemplars to enhance student understanding of quality}

There is a growing body of small-scale studies on the use of exemplars in various subject disciplines, using different numbers of exemplars and varied modes of implementation. The first point to make is that the use of exemplars seems to be generally well-received by students. Students perceive class discussion of exemplars to be useful for their learning (Hendry et al. 2012); they report a high level of engagement with annotated exemplars provided as supplementary resources (Bell et al. 2012); and 
they are receptive to annotated exemplars posted online (Handley and Williams 2011). Exemplars can offer a broader guide to improvement by providing a sense of the bigger picture of coherence and integration, going beyond satisfying a list of criteria (Wimshurst and Manning 2013).

In a key early study, Rust et al. (2003) report on an intervention in which students graded two exemplars of previous student work using teacher-derived assessment criteria, prior to a 90-minute optional workshop. The workshop focused on peer discussion of the grade for the marked samples, teachers' commentaries on the assessment criteria, peer review of grades in light of teacher explanations and provision of annotated teacher marking of the exemplars. The authors conclude that explicit articulation of assessment criteria and standards is insufficient to develop shared understandings between staff and students, and socialisation processes as exemplified by the workshop are necessary for tacit knowledge transfer to occur. The subsequent assessment results indicated that the analysis of exemplars helped participating students perform better in coursework assignments and transfer insights when undertaking similar assessment tasks.

A further relevant study for the current discussion is that of Hendry et al. (2012). This study analysed the use of three exemplars (one fail, one credit, one distinction) focused on a different legal issue to the one first-year law students needed to tackle in their assignments. The co-authors collected data from three different teacher implementers who all used varied pedagogic strategies. All three began with peer discussion of the exemplars and then teacher A prioritised teacher-led discussion; teacher B mainly focused on what was wrong with the exemplars; and teacher $C$ did not follow-up with any dialogue. Students in the class of teacher A were more positive about the activity and achieved higher grades, suggesting that there may be a link between the amount or nature of teacher-led discussion on exemplars and student achievement (ibid 2012). The authors highlight the critical role of teachers' facilitation skills in helping students understand the standards of work embedded in the exemplars and summarised in criteria. From another study, these same researchers suggest that it is the quality of dialogue which seems to be a key factor in mediating students' engagement and development of ownership of usable insights from exemplars (Hendry et al. 2011).

A further important finding from exemplar research is that clarifying the nature of good quality work may support students in understanding teacher feedback (Handley 
and Williams 2011; Hendry 2013; Orsmond et al. 2002). Unless students have an understanding of what teachers are looking for in an assignment, they find it difficult to decode feedback messages. The potential contribution of exemplars to improving feedback processes is particularly useful given the relatively high level of reported dissatisfaction with feedback (see, for example, the recent review by Li and De Luca 2012). In the same way that dialogue is essential to teaching, it is also critical for feedback, at various stages of a learning process and not just after assignments are submitted (Carless et al. 2011; Nicol 2010).

There are, however, a number of challenges facing the use of exemplars. Some students, particularly but not only those in the early stages of their programmes, find it hard to discern quality and may sometimes make unsound judgements about exemplars (Hendry et al. 2012; Sambell et al. 2013). This may provoke doubts in teachers' minds about the value of using exemplars, but could also be taken as a sign that more work around exemplars is required. There are also tensions between time available for content coverage or the discussion of exemplars. Unless teachers are committed to their use, exemplars may remain a supplementary rather than a core aspect of pedagogy.

Some teachers are reluctant to show examples of student work for fear that students may assume that there is a standard required answer (Norton 2004). A related problem arises if students see an exemplar as a model answer and use it uncritically to be imitated or plagiarised (Handley and Williams 2011). In such a case, exemplars may impede student creativity or novel approaches to a task. A counterargument is to discuss several exam- ples so that students can notice that there are different ways in which work expresses quality (Sadler 1987).

The productive transfer or adaptation of insights from exemplars to students' own work is a critical issue. The basic mechanisms for transfer comprise: encoding the notion of quality in different contexts; identifying the differences between exemplars and students' specific assessment task; and developing a mental set for skills application in their own context (Sternberg and Frensch 1993). Transfer of knowledge can be demonstrated in the way students discuss exemplars and how they apply the strategies in their own work (Hickey and Pellegrino 2005). A useful related student strategy is to treat exemplars as a performance base against which to compare their own work as a means of self-regulation (Bell et al. 2012). 
To sum up, there is no strong sense of cumulative exemplar research; rather, the field contains a number of useful studies, each of a different nature and serving a different purpose. There is a consensus that students are receptive to their use, but there is less agreement on how exemplars are shared with them. Different modes include additional optional workshops (Rust et al. 2003), part of regular class (Hendry et al. 2012) and annotated online (Handley and Williams 2011) or offline resources (Bell et al. 2012). Teacher implementation is an important factor; for students to derive optimum benefits from the analysis of exemplars, teachers may need to develop enhanced skills in facilitating and leading discussion around exemplars (Hendry et al. 2012). These key issues prompt us to explore the effective- ness of various kinds of in-class discussion of exemplars. The research question guiding the study is 'How do different types of in-class discussion facilitate student understanding of quality and positive transfer of strategies from exemplars?'

\section{Context and background}

This study was conducted at the post-secondary institution at which the first author is teaching. This institution offers associate degree programmes for secondary school leavers wishing to pursue tertiary education, but not yet able to obtain an undergraduate place. Two cycles of action research were carried out in semester one 2012/13 and semester one 2013/14, respectively: 69 students in three classes (approximately 23 students in each class) participated in the first cycle; and 68 students in three similar class sizes took part in the second one. All participants were native speakers of Chinese, year one business students taking a compulsory English for Academic Studies module. The assessment tasks for this module encompassed a 500-word individual argumentative essay, a writing test and an oral presentation. The discussion of exemplars supported the preparation of the essay. The same exemplars were used in both cycles: authentic previous student work in the same genre to that required in the assessment task. Consent was obtained from those students whose work provided exemplars. To minimise the likelihood of unproductive copying from exemplars, the topics in the exemplars and students’ actual tasks were different.

\section{Method}

\section{Action research}


This study adopted Norton's (2009) approach to action research, which depicts the exploratory process as involving four major stages: observing, planning, acting and reflecting. These stages were implemented through two cycles, which we now describe. The general initial observation was that using exemplars has potential but is difficult to organise and implement effectively. Drawing on the research of Rust et al. (2003) and Hendry et al. (2012), we planned to incorporate peer discussion and teacher-led interaction about two (one good and one weak) exemplars into classroom teaching. The specific preparation for the activity involved the teacher-researcher (the first author) eliciting from students the criteria for successful completion of the task. This act could establish common ground for subsequent discussion so that they discussed exemplars based on specific criteria: strategies to introduce topic, use of supporting evidence, organisation and language usage. Then, in groups of three or four, they were asked to distinguish the good from the weak exemplar and identify the characteristics of and strategies used in each one. The peer discussion was followed by teacher-led interaction in which the teacher- researcher invited individual students to comment on the exemplars and share their ideas in relation to preparing their own related assignments. The entire intervention took around one hour of class time.

The reflecting stage involves data collection (described in the subsequent sub-section) for evaluating the intervention and the teacher-researcher's reflections for improving student learning and pedagogical practice (Norton 2009). Based on the collected data, she carried out reflection-on-practice guided by a strengths-based reflective framework (Ghaye 2011). This frame- work was selected because its emphasis on both the strengths and weak- nesses of an intervention enabled her to appreciate and understand her own practice so that she could consider other possibilities for cycle two.

\section{Data collection}

Data were collected from three sources: student participants, a critical friend and a teacher-researcher journal. First, to ascertain students' opinions about the intervention, all students completed an open-ended survey at the end of the class on the use of exemplars. For further exploration of their views, approximately one-third of the participants in each class participated in focus group interviews (see Appendices 1 and 2 for the questions in the sur- vey and focus group interviews, respectively). All data were collected in Chinese (their mother tongue) and translated into English for analysis.

Second, cognisant of the challenge posed by subjectivity in action research, an 
experienced colleague was invited to act as a critical friend. The critical friend played the role of a teaching consultant (Kember 2000) commenting on the effectiveness of the intervention and providing advice for pedagogical enhancement. She was chosen because she had expressed an interest in using exemplars in her classes. In each cycle, she observed one class and watched in her own time extracts from videotapes of other lessons. She was interviewed after each cycle to comment on the strengths and weaknesses of the intervention and to share her experience of exemplar use.

Third, the teacher-student interaction and student presentations were videotaped and observed for the purpose of reflection. Upon observing the videos after each exemplar class, the teacher-researcher compiled a journal entry of approximately 300 words. The focus of the entries was on documenting details of the intervention, commenting critically on pertinent aspects and considering alternatives to improve practice.

\section{Data analysis}

We reviewed different forms of data to identify the main issues related to the implementation of the intervention. Initial codes were based on those issues suggested by the literature review and were expanded further through iterative examination of open-ended survey forms and interview transcripts. Similar codes were grouped to form categories of ideas or themes. For the themes identified from the survey, we conducted a frequency count and then converted the numbers into percentages to indicate main trends in the findings. For better illustrative effect, only themes which are highly relevant to exemplar use are shown in tables and discussed in detail. Based on the major themes identified, we looked for pertinent quotes in the interviews to further explore participants' perceptions. Some themes emerged more prominently from the interviews and these themes are also discussed in the findings. All data analysis was done by the first author. The second author (the doctoral supervisor) took the role of challenging the first author to justify her interpretation of the available evidence. The preliminary analysis was passed to the student interviewees and the critical friend for member checks. There was no misinterpretation of their opinions, and the critical friend added more examples for elaboration.

Triangulation between the data sets from different parties is a major means of establishing trustworthiness. We utilised a role-ordered matrix (Miles and Huberman 1994) to compare the opinions of the student participants, critical friend and teacher-researcher. In the case of divergent views, we examined possible reasons for different viewpoints. We endeavour to demonstrate clearly in the findings student voice, views of the critical friend 
and teacher-researcher journal entries in order to show the distinct opinions of the three parties.

\section{Findings}

We present the findings according to the action research cycles. Since both cycles commenced with peer discussion and there were no significant differences in its handling in the two cycles, it is examined first. This sub-section is followed by teacher-led interaction in cycle one and student mini-presentations on exemplars in cycle two.

\section{Peer discussion}

Peer discussion of exemplars was carried out in both cycles with the aims of allowing students to articulate their opinions about the characteristics of the exemplars and to obtain cognitive and emotional support from their peers. In responding to the open-ended survey question 'What do you think of peer discussion of the two sample essays?', students highlighted the role of peer discussion as a means to clarify concepts and brainstorm ideas. The main themes for both cycles are summarised in Table 1.

Some representative views from the focus group interviews are as follows:

I like discussing with peers as they can help me clarify concepts. Teacher's explanations are sometimes too abstract and difficult to understand. My group members used simple words and gave better illustrative examples to help me understand the main ideas. (Cycle one)

I quite like the discussion. Through explaining the concepts to others, we can generate more ideas. I know I understand more about academic writing as I could rephrase the ideas. This gave me more confidence. (Cycle one)

Table 1 Students' perceptions of peer discussion around exemplars

\begin{tabular}{ccccc}
\hline Theme & Clarify concepts & $\begin{array}{c}\text { Communicate with } \\
\text { peers }\end{array}$ & Brainstorm ideas & $\begin{array}{c}\text { Interesting } \\
\text { method }\end{array}$ \\
\hline $\begin{array}{c}\text { Cycle One } \\
\mathrm{n}=69\end{array}$ & $42.9 \%$ & $18.4 \%$ & $20.4 \%$ & $4.1 \%$ \\
\hline $\begin{array}{c}\text { Cycle Two } \\
\mathrm{n}=68\end{array}$ & $30.0 \%$ & $29.5 \%$ & $23.0 \%$ & $14.8 \%$ \\
\hline
\end{tabular}


In a small group, I was not afraid of raising questions. If I asked the same question in front of the whole class, I might feel embarrassed. (Cycle two)

I'm not sure if the discussion helped me distinguish good work from poor work. They tried to persuade me that the first sample is better. We are all students, still learning about how to write an essay. Their ideas may not be correct. I want to know the teacher's judgement. (Cycle two)

In the main, students found peer discussion of exemplars useful for their learning as they could clarify concepts with classmates, generate ideas and develop confidence. The final quotation comes from a student who appeared sceptical about the competence of his peers in judging the samples and wanted to know the teacher's viewpoint. This could provide him with some motivation to engage with the teacher-led dialogue in the next stage of the class.

In relation to the usefulness of peer discussion, the critical friend expressed her views in the following:

The peer discussion greatly increased student participation. For those who seldom speak in class, they listened attentively to others and raised questions. I think they benefited a lot from their 'assistant teachers'. But I have the feeling that most groups concentrated on the merits of the good sample. Few discussed the weaknesses of the good sample or how to improve the weaker one. (Cycle one)

The critical friend notes different forms of participation, including learning by listening and being in a situation where it is easier to raise questions than in whole-class teacher-led interaction. We also infer that she perceives the analysis could go deeper in terms of thinking more about how to improve the weaker sample or even noting limitations of the stronger sample.

The teacher-researcher reflected on the effectiveness of peer discussion in one of her journal entries:

The peer discussion is successful in terms of students being able to identify the good sample and mention the strategies used. But it seems like the value of peer discussion is confined to exchanging knowledge. To what extent can it facilitate 
In sum, it appears that the value of peer discussion of exemplars is three-fold. First, it provides students with an opportunity to discuss features of academic writing. Second, there are opportunities for negotiation of meaning or scaffolding of student knowledge, for example, less competent students deriving cognitive support from more capable peers. Third, the supportive environment of the small group has potential for affective gains: increasing student participation, bolstering confidence or creating a favourable environment for seeking clarifications. This type of discussion seems to be a useful starting point but it may not be sufficient to engender students' transfer of strategies from exemplars to their own assessment task. As asserted by the critical friend, many students concentrated on identifying strategies in the good exemplar, a comparatively straightforward task, and few attempted to share their own insights obtained from the exemplars. This can be attributed to the specification of the discussion task, but it also indicates a need for further critical analysis of the exemplars, including, for example, additional teacher-led interaction.

\section{Teacher-led interaction on exemplars}

Teacher-led interaction is a distinctive feature of cycle one. It was developed through a whole-class discussion in which the teacher elicited from selected students their opinions about which exemplar was superior, and asked them to identify the strategies used in the good exemplar and to share their insights on applying the strategies in their own assignment. They were able to identify the stronger sample and pinpoint relevant strategies, for example the use of questioning to grab reader attention and the use of examples and figures as supporting evidence in body paragraphs. For the survey question 'What do you think of teacher-student discussion of the two sample essays?', a major finding was that the discussion was generally helpful in supporting student understanding of task requirements. The main results are presented in Table 2.

Table 2 Students' perceptions about teacher-student discussion around exemplars

\begin{tabular}{ccccccc}
\hline Theme & $\begin{array}{c}\text { Understand task } \\
\text { requirements }\end{array}$ & $\begin{array}{c}\text { Learn from } \\
\text { exemplars' } \\
\text { strengths \& } \\
\text { weaknesses }\end{array}$ & $\begin{array}{c}\text { Encourage } \\
\text { self-regulation }\end{array}$ & $\begin{array}{c}\text { Teacher } \\
\text { explanation } \\
\text { useful }\end{array}$ & $\begin{array}{c}\text { Clear } \\
\text { writing } \\
\text { direction }\end{array}$ & $\begin{array}{c}\text { Too much } \\
\text { teacher } \\
\text { talk }\end{array}$ \\
\hline Cycle One & $49.0 \%$ & $30.6 \%$ & $24.5 \%$ & $16.1 \%$ & $12.2 \%$ & $4.1 \%$ \\
\hline
\end{tabular}


Some representative student views from the focus group interviews are captured below:

Before the discussion, I just thought grade A essay meant perfect grammar and use of varied vocabulary. Now, I understand it also requires use of appropriate strategies to draw reader attention in the introduction and use of examples and statistics as supporting evidence. I know what should be included in the essay and I have more confidence to do the assignment. (Cycle one)

Before reading the samples, I mainly checked spelling and grammar when doing proofreading. After this activity, I will check if I can avoid the mistakes in the poor sample and read the good one to see if my work is comparable in terms of quality. (Cycle one)

The discussion made me think about the differences between the sample and my work. The sample is about unethical restaurant owner, while my essay discusses minimum wage. To develop my work, I need both examples and figures like unemployment rate as supporting evidence. (Cycle one)

Producing insights for my own essay is difficult. I did not know how to do it at first. Fortunately, the teacher used questions like 'What would readers want to know for background if they know nothing about social enterprise?' to guide me. (Cycle one)

From the first quotation, we infer a development in student thinking from seeing English writing as being mainly about grammatical accuracy and language usage (influenced by their previous experience of language learning in secondary schooling) towards a more developed understanding of the requirements of an academic essay. The second quotation suggests an awareness and expressed intention to use the exemplars in regulating one's own work. The third quotation suggests that the student recognises the con- textual differences between the exemplar and his own work. The last one is indicative of a student trying to overcome a challenge in generating insights by drawing on the teacher guidance.

Regarding the effectiveness of the teacher-led discussion, the critical friend 
commented as follows:

The students are attentive, perhaps because they think discussing the characteristics of a well-written essay is important for their assignment ... I was wondering if there was another way to conduct the discussion. Can student voice be expressed if they are just required to answer questions? (Cycle one)

The part of sharing insights is interesting. An alternative approach is to ask students to revise the weak exemplar. This is another way to make them apply the strategies in a meaningful manner. (Cycle one)

This comment raises the important issues of expression of student voice and alternative ways to develop their critical thinking skills. The teacher- researcher also reflected on this issue in her journal:

The discussion helped students understand how I will assess their work. But it was not very interactive. I planned the dialogue carefully in order to have students' responses fit in my 'discussion plan'. To increase student ownership of learning, I could have asked them to explain the details rather than doing it myself. Perhaps in cycle two, I can make students play an active role in the discussion. (Cycle one)

In summary, the students, critical friend and teacher-researcher hold a consistent view that teacher-led interaction on exemplars has potential in illustrating the notion of quality. Divergence of opinion is expressed among the three parties regarding the dominance of teacher-led discussion; $4.1 \%$ of students felt this was not an issue but the critical friend and teacher- researcher found it problematic. This discrepancy could be explained by students' emphasis on short-term learning gains, completion of assignment and assessment results, whereas the other two parties focus on long-term learning goals and development of learner agency. Upon reflection, this activity might have been modified to increase student ownership of learning. Based on the critical friend's sharing of her experience, the teacher-researcher decided to replace the teacher-led discussion with a somewhat more student-centred activity in cycle two.

\section{Student mini-presentations on exemplars}

In cycle two, after the peer discussion students were further asked to work with their group members to point out the problems in the weak sample and make suggestions for 
improvement. Then, two groups of four in each class presented their ideas. The first group made a short presentation analysing the good sample, and the second group presented suggestions on improving the weak sample. The teacher acknowledged their ideas, elaborated on selected points or used questions to stimulate their thoughts at the end of each presentation. For the question 'What do you think of student presentations of the good sample?', the most salient feature was that the mini-presentations were thought to be a way to demonstrate knowledge. The main themes are summarised in Table 3.

Table 3 Students' perceptions about student mini-presentations on exemplars

\begin{tabular}{ccccccc}
\hline Theme & $\begin{array}{c}\text { Demonstrate } \\
\text { knowledge }\end{array}$ & $\begin{array}{c}\text { Student-ce } \\
\text { ntred } \\
\text { activity }\end{array}$ & $\begin{array}{c}\text { Compare } \\
\text { one’s } \\
\text { ideas with } \\
\text { presenters' }\end{array}$ & $\begin{array}{c}\text { Oral } \\
\text { practice }\end{array}$ & $\begin{array}{c}\text { More } \\
\text { presentations } \\
\text { expected }\end{array}$ & $\begin{array}{l}\text { Importance of } \\
\text { teacher } \\
\text { feedback }\end{array}$ \\
\hline $\begin{array}{c}\text { Cycle } \\
\text { Two }\end{array}$ & $23.0 \%$ & $14.8 \%$ & $14.8 \%$ & $13.1 \%$ & $11.5 \%$ & $8.2 \%$ \\
n=68 & & & & & & \\
\hline
\end{tabular}

In the subsequent focus group interviews, selected student views are as follows:

I benefited a lot as our group was required to point out the strategies used in the good sample. This was a good learning experience as we had to organise our thoughts and use our own words to comment on the sample. This reinforced our understanding of the writing strategies. (Cycle two)

When I listened to their presentations, I would compare if the presenters and I got the same points ... The most useful part is the teacher's feedback on their presentation. The teacher confirmed whether our understandings were correct and told us more points about the samples which were not mentioned by the peers. (Cycle two)

I hope more groups could do such presentation to get more experience in analysing essays. (Cycle two)

In summary, students interpreted the mini-presentations as an opportunity to demonstrate knowledge. Another feature that emerged specifically in some interview data was the role of teacher feedback on the presentations and her elaboration of some relevant 
points. As suggested in the third quotation, a possible development would be to increase student involvement further by allowing more students to share their ideas.

For the question 'What do you think of asking students to revise the weak sample?', Table 4 shows that the revision processes had some benefits, such as helping students avoid making similar mistakes in their own work. As students stated:

Discussing how to improve the weak sample is useful. Being able to identify the weaknesses and improve them are two different things. We knew the problems, but we had no idea how to improve the quality. Rewriting the weak sample makes me realise my own problems when writing the essay. (Cycle two)

The revising task is a good chance for practice. But even if I can improve the weak sample, I still make mistakes in my own work. The best reference tool should be my work with teacher feedback on it. (Cycle two)

The first quotation suggests that, for students to develop their critical aware- ness, they should be given an opportunity to recognise and overcome the inadequacies of a weaker sample. The second quotation reminds us of the importance of individualised feedback. A related inference is that a way for- ward might involve interplay between the use of exemplars and teacher feedback. Teacher feedback to stimulate their thoughts or indicate their performance gap is important during the process of applying insights to one's own work.

Table 4 Students' perceptions of revising weak exemplar

\begin{tabular}{cccccc}
\hline Theme & $\begin{array}{c}\text { Avoid similar } \\
\text { mistakes in } \\
\text { own work }\end{array}$ & $\begin{array}{c}\text { Serve as } \\
\text { reference } \\
\text { material }\end{array}$ & $\begin{array}{c}\text { Opportunity } \\
\text { for } \\
\text { application }\end{array}$ & $\begin{array}{c}\text { Encourage } \\
\text { self-reflect } \\
\text { ion }\end{array}$ & $\begin{array}{c}\text { Need feedback } \\
\text { on one's own } \\
\text { work }\end{array}$ \\
\hline $\begin{array}{c}\text { Cycle } \\
\text { Two }\end{array}$ & $34.7 \%$ & $32.7 \%$ & $20.4 \%$ & $14.3 \%$ & $6.1 \%$ \\
$\mathrm{n=68}$ & & & & & \\
\hline
\end{tabular}

The critical friend expressed her views on student presentations and sharing ideas on revising the weak exemplar as follows: 
Compared to cycle one, students are given more responsibility to be in charge of their learning. This is a good chance for knowledge demonstration, but the presentation quality depends on their abilities. I noticed that less capable students need more guidance in articulating ideas. (Cycle two)

The student presentation and the subsequent teacher response are a good way to develop their analytical and critical mind, which is highly related to strategies application. But getting them to transfer insights is not easy. They may encounter a wide variety of language problems in the process. (Cycle two)

The teacher-researcher reflected on the change from teacher-dominated discussion to student-centred activity in her journal:

Students are more engaged in the process ... The most critical part is my response to their presentations. It was essential to give explanation if they misinterpreted some concepts. I found it useful when I shared other examples to clarify their misunderstanding and further illustrate the application of strategies in other contexts. (Cycle two)

Getting students to improve the weaker sample seems effective in developing their critical awareness. However, not all of them could make suggestions to improve the weak sample. I need to give them more guidance like using more examples and raising some questions. (Cycle two)

In short, the mini-presentations were considered by all parties to be useful in demonstrating knowledge learnt, increasing student agency and promoting transfer of strategies from exemplars to the students' own assessment task. Revising the weak exemplar affords students an opportunity to gain some experience of trying to tackle some writing problems and seek timely guidance and feedback from the teacher. Providing students with such opportunity is a starting point for positive transfer, but particularly important is the quality of teacher guidance and assistance. Comparing student learning experience in both cycles, we infer that the more students are engaged in the exemplar activity, the deeper the understanding of writing strategies and assessment standards they can acquire from the learning process.

\section{Discussion}


This exploratory study addressed the issue of how in-class discussion of exemplars can enhance student understanding of quality and facilitate positive transfer of strategies. Peer discussion and student mini-presentations allowed students to articulate their views and to receive peer and teacher feedback on their interpretations. Teacher-led interaction served to mediate student views and to highlight key aspects of good quality academic writing. These processes appeared to be useful in communicating task requirements and arousing critical awareness of the need to transfer strategies.

Most of the literature on exemplars relates to the university sector, whereas our study was conducted in post-secondary education. The participants in our research are generally less confident and competent than their undergraduate counterparts, and the findings suggest that they need more scaffolding when developing their understanding of assessment requirements embedded in exemplars. Peer dialogue is useful in fostering a supportive environment for negotiation of meaning and encouraging active student participation. The teacher-led interaction and related guidance can serve as further scaffolding that helps them gradually progress from peripheral towards fuller participation in an academic community (Hickey and Pellegrino 2005).

If we relate this study to other literature on exemplars, our study corroborates the findings of Hendry et al. (2012) and Rust et al. (2003) that through peer and teacher-led discussion, exemplars have the potential to explain tacit knowledge and illustrate teacher conceptions of quality. These two studies and ours differ from those of Handley and Williams (2011) and Bell et al. (2012) in promoting classroom-based discussion rather than exposure to annotated exemplars for student self-study. Our position is that the use of exemplars is most productive when students are actively involved in classroom discussion of exemplars, so that there are opportunities for negotiation of meaning with peers and the teacher. Accordingly, a central message from our study is the importance of student participation in different types of discussion to maximise the potential of analysing exemplars. We call this dialogic use of exemplars.

Teachers often feel pressured in terms of covering course content; thus finding sufficient curriculum space for dialogic use of exemplars may some- times be challenging in the face of practical time constraints. This is probably why some studies (Bell et al. 2012; Handley and Williams 2011) did not use regular classroom time for analysing exemplars. A useful strategy noted by Sambell et al. (2013) is for students to complete their reading and analysis of exemplars before coming to class, so preserving 
more classroom time for critical discussion. Posting exemplars on an online learning system is an option, but given our emphasis on in-class dialogue we doubt whether it is an optimum mode of implementation unless it can be engineered to promote significant student discussion and teacher feedback.

Our study also addresses a point raised in the literature that measures need to be taken to discourage unproductive imitation of exemplars. Our intervention tackled this issue through three main strategies. The first, simply enough, was in setting a course assignment that shared a close resemblance to the exemplars in genre but variations in context and topic requirements. This encourages students to use rhetorical strategies from the samples without copying content. The second was making use of teacher-student dialogue and student mini-presentations to develop critical aware- ness of the differences between exemplars and the actual assessment task. If we apply the transfer mechanisms suggested by Sternberg and Frensch (1993) to interpret this part of the intervention, we infer that student sharing of insights facilitates their capacity to discriminate features of the exemplars relevant to their own task. In doing so, they are required to contextualise knowledge and establish a mental set for transfer. The third was providing an opportunity for students to apply and practise use of strategies with guidance and support from the teacher. In this way, teacher guidance serves as a symbolic artefact mediating student understanding of quality and advancing their zone of proximal development (Vygotsky 1978).

As regards evidence of positive transfer, the outcomes in the form of students' final assignments were mainly encouraging. Students generally used their own words to follow patterns suggested in the exemplars: capturing reader attention; providing relevant background information; and developing thesis statements. There were, however, a few occasions when students borrowed a phrase from the exemplars and used it inappropriately. Imitation and textual borrowing are complex areas of writing and we tentatively suggest that positive imitation may involve appropriating patterns and writing conventions, whereas negative imitation is indicated by copying without deep understanding. There may be grey areas and complexities of interpretation between these two poles which require further exploration.

Another key aspect arising from our analysis is the role of teacher mediation in the discussion process. In this study, teacher mediation seems to perform dual functions. The first is to give students commentary and reinforcement regarding the extent to 
which they have grasped ideas from the exemplars appropriately. The second involves teacher feedback on effective strategies to facilitate positive transfer. From students' perspectives, developing insights from exemplars can be cognitively demanding. Teachers can use prompts and elicitation to stimulate students' thoughts and provide appropriate scaffolding. This suggests a possible interplay between exemplars and teacher feedback. For example, analysis of exemplars has potential in supporting general student decoding of feedback messages, whereas individualised feedback plays a more specific role in providing commentary on student work.

Regarding the limitations of this study, one of them is the issue of subjectivity and personal involvement of the researcher. This challenge was tackled by the presence of the critical friend on site and dialogues between the co-authors which brought a further level of reflection into interpretation. A second limitation is that teacher-student power relations may discourage students from voicing their honest opinions, especially regarding inadequacies of the intervention. Although we cannot assume that this did not occur, the critical friend was particularly helpful in providing an alternative voice to the students' viewpoints. A third limitation is that our research design did not afford a quantitative analysis of relationships between the intervention and student achievement, so any improvement in the quality of student work is based solely on participants' perceptions.

\section{Conclusion}

This article discussed the potential for dialogic use of exemplars to support student understanding of quality. We explored the dialogic use of exemplars in explicating academic knowledge and facilitating transfer of insights from exemplars to students' own work. For positive transfer to occur, teachers need to plan various forms of discussion around exemplars and also react adroitly to on-going interaction with students. Under these circumstances, there is potential for students to improve their understanding of quality, develop their critical thinking skills and enhance their ability to self-regulate their own related work.

A fruitful line of further research is to examine in more detail the potential of dialogic use of exemplars to promote student interpretation and uptake of feedback. We believe that exemplars have a particularly useful role to play in supporting the enhancement of feedback processes because they help students to see what teachers are looking for in an assignment answer, and so may facilitate student engagement with 
constructive feed- back. Further research could explore the relationship between analysing exemplars and student understanding and uptake of feedback. Under what circumstances might dialogic use of exemplars facilitate student engagement with feedback.

\section{References}

Bell, A., R. Mladenovic, and M. Price. 2012. "Students' Perceptions of the Usefulness of Marking Guides, Grade Descriptors and Annotated Exemplars.” Assessment \& Evaluation in Higher Education 38 (7): 769-788.

Carless, D., D. Salter, M. Yang, and J. Lam. 2011. "Developing Sustainable Feedback Practices.” Studies in Higher Education 36 (4): 395-407.

Ghaye, T. 2011. Teaching and Learning through Reflective Practice: A Practical Guide for Positive Action. New York: Routledge.

Handley, K., and L. Williams. 2011. "From Copying to Learning: Using Exemplars to Engage Students with Assessment Criteria and Feedback.” Assessment \& Evaluation in Higher Education 36 (1): 95-108.

Hendry, G. D. 2013. “Integrating Feedback with Classroom Teaching: Using Exemplars to Scaffold Learning." In Reconceptualising Feedback in Higher Education: Developing Dialogue with Students, edited by S. Merry, M. Price, D. Carless, and M. Taras, 133-141. Abingdon: Routledge.

Hendry, G., S. Armstrong, and N. Bromberger. 2012. "Implementing Standardsbased Assessment Effectively: Incorporating Discussion of Exemplars into Classroom Teaching.” Assessment \& Evaluation in Higher Education 37 (2): 149-161.

Hendry, G., N. Bromberger, and S. Armstrong. 2011. "Constructive Guidance and Feedback for Learning: The Usefulness of Exemplars, Marking Sheets and Different Types of Feedback in a First Year Law Subject.” Assessment \& Evaluation in Higher Education 36 (1): 1-11.

Hickey, D., and J. Pellegrino. 2005. “Three Dimensions for Understanding Transfer and Student Assessment." In Transfer of Learning from a Modern Multidisciplinary Perspective, edited by J. P. Mestre, 251-293. Greenwich, CT: Information Age Publishing.

Kember, D. 2000. Action Learning and Action Research: Improving the Quality of Teaching and Learning. London: Kogan Page. 
Kemmis, S., and R. McTaggart. 1988. The Action Research Planner. 3rd ed. Victoria: Deakin University Press.

Li, J., and R. De Luca. 2012. "Review of Assessment Feedback.” Studies in Higher Education, iFirst Article. DOI:10.1080/03075079.2012.709494.

Miles, M., and A. Huberman. 1994. Qualitative Data Analysis: An Expanded Sourcebook. 2nd ed. Thousand Oaks, California: Sage.

Nicol, D. 2010. "From Monologue to Dialogue: Improving Written Feedback Processes in Mass Higher Education.” Assessment \& Evaluation in Higher Education 35 (5): 501-517.

Norton, L. 2004. "Using Assessment Criteria as Learning Criteria: A Case Study in Psychology.” Assessment and Evaluation in Higher Education 29 (6): 687-702.

Norton, L. 2009. Action Research in Teaching and Learning: A Practical Guide to Conducting Pedagogical Research in Universities. Abingdon: Routledge.

Orsmond, P., S. Merry, and K. Reiling. 2002. "The Use of Exemplars and Formative Feedback When Using Student Derived Marking Criteria in Peer and Selfassessment.” Assessment \& Evaluation in Higher Education 27 (4): 309-323.

Price, M., C. Rust, B. O’Donovan, and K. Handley. 2012. Assessment Literacy: The Foundation for Improving Student Learning. Oxford: Oxford Centre for Staff and Learning Development.

Rust, C., M. Price, and B. O’Donovan. 2003. “Improving Students’ Learning by Developing Their Understanding of Assessment Criteria and Processes.”Assessment \& Evaluation in Higher Education 28 (2): 147-164.

Sadler, D. R. 1987. "Specifying and Promulgating Achievement Standards.” Oxford Review of Education 13: 191-209.

Sadler, D. R. 2002. “Ah! .. So That’s Quality.” In Assessment Case Studies, Experience and Practice from Higher Education, edited by P. Schwartz and G. Webb, 130-136. London: Kogan Page.

Sadler, D. R. 2010. "Beyond Feedback: Developing Student Capability in Complex Appraisal.” Assessment \& Evaluation in Higher Education 35 (5): 535-550.

Sambell, K., L. McDowell, and C. Montgomery. 2013. Assessment for Learning in Higher Education. London: Routledge.

Sternberg, R., and P. Frensch. 1993. "Mechanisms of Transfer." In Transfer on Trial: Intelligence, Cognition and Instruction, edited by D. K. Detterman and R. J. Sternberg, 25-38. Norwood, New Jersey: Ablex Publishing.

Vygotsky, L. S. 1978. Mind and Society: The Development of Higher Psychological 
Processes. Cambridge, MA: Harvard University Press.

Wimshurst, K., and M. Manning. 2013. "Feed-forward Assessment, Exemplars and

Peer Marking: Evidence of Efficacy.” Assessment \& Evaluation in Higher Education 38 (4): 451-465.

\section{Appendix 1. Questions in open-ended surveys}

Cycle one:

(1) What do you think of peer discussion of the two sample essays?

(2) What do you think of teacher-student discussion of the two sample essays?

(3) What do you think of asking students to share how they apply strategies in their own work?

(4) Do you have any suggestions to improve this activity?

Cycle two:

(1) What do you think of peer discussion of the two sample essays?

(2) What do you think of student presentations of the good sample?

(3) What do you think of asking students to revise the weak sample?

(4) Do you have any suggestions to improve this activity? 


\section{Appendix 2. Questions in focus group interviews}

Cycle one:

(1) Can the peer discussion of the two sample essays help you do your assignment? If yes, how did it help you? If no, why not?

(2) Did you encounter any problems in the peer discussion? If yes, could you resolve the problems?

(3) Can the teacher-student discussion of the two sample essays help you do your assignment? If yes, how did it help you? If no, why not?

(4) Was it easy for you to generate insights from the samples to apply to your own assignment?

(5) Did you use the insights you obtained from the exemplars to monitor your work? If yes, how? If no, why not?

(6) Do you have any suggestions to improve this activity?

Cycle two:

(1) Can the peer discussion of the two sample essays help you do your assignment? If yes, how did it help you? If no, why not?

(2) Did you encounter any problems in the peer discussion? If yes, could you resolve the problems?

(3) Can the student presentations help you understand task requirements and assessment criteria? If yes, how did they help you? If no, why not?

(4) Did you encounter any problems in revising the weak sample? If yes, what were the problems? Could you resolve the problems?

(5) Did you use the insights you obtained from the exemplars to monitor your work? If yes, how? If no, why not?

(6) Do you have any suggestions to improve this activity? 